\section{Gravity experiment sparks spat between physicists}

Geoff Brumfiel, Seattle

Physicists are falling out over a highprofile claim that the speed at which gravity propagates closely matches the speed of light.

The row began after two researchers said that they had measured the 'speed of gravity' for the first time and found that, like the speed of light, it is finite.

Sergei Kopeikin, a theoretical physicist at the University of Missouri in Columbia, and Edward Fomalont, an astronomer at the National Radio Astronomy Observatory in Charlottesville, Virginia, revealed their results on 7 January, at the American Astronomical Society's annual meeting in Seattle.

The pair measured the refractive effects of Jupiter's gravitational field on the radio waves emitted by a bright, distant galaxy. From this they were able to determine that gravity propagates at close to the speed of light.

The value is similar to that predicted by Einstein, but several theorists were quick to assert that Fomalont and Kopeikin's interpretation of their results - which was widely reported around the world last week - is flawed.

"It's complete nonsense," says Peter van Nieuwenhuizen, a physicist at Stony Brook University in New York, who has devoted much of his career to studying gravity. Clifford Will, a physicist at Washington University in St Louis, Missouri, adds that he believes that the team's experimental set-up could theoretically yield gravity's speed of propagation. But Will's calculations suggest that the effect would be too small to detect with any existing telescope.

"The experiment is wonderful, but it has nothing to do with the speed of gravity," says Kenneth Nordtvedt, a retired physics professor at Montana State University in Bozeman. Nordtvedt says that the team is actually seeing a gravitational analogue of the force of magnetism, created by electrons moving at close to the speed of light.

"I think Dr Nordtvedt is confused," says Kopeikin. To get his speed-of-gravity interpretation, Kopeikin used his own simplified version of Einstein's gravity equations, which other theorists, such as Nordtvedt, have yet to fully accept. "The situation is a little upsetting for us," says Fomalont, who took the experimental measurements - adding that he hopes the quarrelling theorists will get together soon and settle their differences.

\title{
Safety doubts force rethink of embattled comet mission
}

Declan Butler, Paris

Rosetta, the US\$700-million European Space Agency (ESA) mission to land a probe on the comet Wirtanen in 2011, is set to miss its January take-off window and could be postponed for a year or more, Nature has learned.

The mission's postponement was set to be agreed on 14 January, after the failure of the Ariane 5 ECA 'heavy lifter' rocket on its maiden flight in December (see Nature 420, 723 ; 2002) cast doubt on the safety of the standard Ariane 5 model, on which Rosetta was scheduled to fly.

Hopes that the launch would go ahead before the take-off window closes on 31 January were temporarily boosted last week, when an inquiry traced the cause of the accident to a cooling fault on the new engine suggesting that the standard rocket is not at risk. And scientists at a pre-launch press briefing in London on 13 January said that they were still hoping for a January launch.

David Southwood, ESA's director of science, was scheduled to hold another briefing in Paris on 15 January "to take stock of the status of this mission". But Nature has learned that Arianespace, which operates the Ariane rockets, has advised against a launch — and ESA has agreed with its assessment. Southwood has previously said: "If there was the slightest risk in my mind, we would not

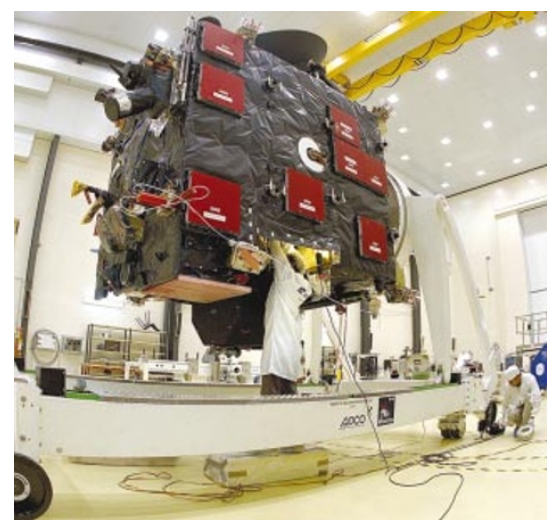

All dressed up, but nowhere to go: the Rosetta probe is set to miss its rendezvous with a comet.

launch; there is no way I'm not going to gamble a billion euros of other people's money."

The quickest alternative launch options would use gravitational assistance from Venus instead of Mars to swing the craft towards Wirtanen - but this would raise heat problems. Others would use Mars, as in the original plan, but this would mean finding a different comet to land on instead of Wirtanen. Sources close to ESA say that no plan will be finalized before a thorough analysis has been undertaken of the cost, scientific merit and technical risk of all options.

\section{Report backs Smithsonian research}

\section{Erika Check, Washington}

Researchers at the Smithsonian Institution (SI) in Washington DC are hoping that 2003 will mark a fresh beginning for science at the world's largest museum complex. That's because an independent panel has endorsed their work - and added that their main problems are a lack of leadership and money.

In a long-awaited report released on 7 January, the Smithsonian Science Commission says that research at the museums is "flourishing", but could "slip ... into a state of mediocrity from which it will be hard to recover" without more financial support. It says that the museums should try to secure more money from Congress, private sources and National Science Foundation grants.

The independent commission, chaired by Jeremy Sabloff, director of the University of Pennsylvania Museum of Archaeology and Anthropology in Philadelphia, says that aside from cash, lack of leadership and vacancies in key positions — such as the directorship of the National Museum of Nat- ural History — have been "the most important factor in the weakening of SI science".

The Smithsonian's Board of Regents set up the commission in July 2001 after researchers publicly clashed with Smithsonian secretary Larry Small over several of his decisions (see Nature 410, 727; 2001).

"We're glad that the report supports the value of science in the institution," says Bernard Finn, curator of electrical collections at the National Museum of American History and chair of the Smithsonian Congress of Scholars. "But the downside of stressing the need for more funding is that it allows the administration to say that we have to be content with losing staff and other resources, if they can't get more money."

Congressional staff members agree that it will be difficult to find more money for Smithsonian science amid a federal budget deficit and worries about an impending war in Iraq. But they say that the report's positive assessment of science at the Smithsonian should help its case. 